\title{
Low Dose Total Body Irradiation for Relapsed Low Grade Non-Hodgkin's Lymphoma: Experience of National Cancer Institute, Cairo
}

\author{
Yasser Bayoumi ${ }^{*}$, Aida Radwan ${ }^{2}$ \\ ${ }^{1}$ Radiation Oncology Department, National Cancer Institute, Cairo University, Cairo, Egypt \\ ${ }^{2}$ Medical Physics Department, National Cancer Institute, Cairo University, Cairo, Egypt \\ Email: ${ }^{*}$ yasserbayoumi777@yahoo.com
}

Received 22 October 2014; revised 23 November 2014; accepted 3 December 2014

Academic Editor: Sibu P. Saha, University of Kentucky, USA

Copyright (C) 2015 by authors and Scientific Research Publishing Inc.

This work is licensed under the Creative Commons Attribution International License (CC BY).

http://creativecommons.org/licenses/by/4.0/

(c) (i) Open Access

\section{Abstract}

Background and Purpose: The relapsed low grade non-Hodgkin's lymphoma (LG-NHL) is currently incurable disease and the optimal treatment regimen has not determined yet. Low dose total body irradiation (LTBI) provides an alternative mechanism of action against cancer cells rather than direct cell kill. The mode of action of LTBI is immune-modulatory effect, induction of apoptosis and hypersensitivity to low radiation doses. The aim of our study is to evaluate the effect of LTBI on relapsed LG-NHL and reporting our experience at National Cancer Institute, Cairo (NCI, Cairo). Material and Methods: Fifty eight patients with relapsed LG-NHL and received LTBI studied retrospectively. LTBI dose was $1.6 \mathrm{~Gy} / 8$ fractions divided on 2 courses; each course 4 fractions treated over 4 days with 2 weeks rest between the 2 courses. Results: The median age is 54 years; $65 \%$ of the patients are men. Forty (69\%) patients had performance status of 2 or more. Twenty seven patients were stage II/III and 31 patients $(53 \%)$ had stage IV disease. Twenty six $(45 \%)$ patients had bulky disease more than $10 \mathrm{~cm}$ and $22(38 \%)$ patients had B symptoms at the time of relapse. The extranodal disease was present in 17 patients $(29 \%)$ and $78 \%$ of the patients received $\geq 3$ regimens of chemotherapy before referral to LTBI. Twenty three patients received IFRT (mean dose $32 \pm 4$ Gy) to initially bulky sites after LTBI. Fourteen patients (24\%) achieved complete remission (CR) while $45 \%, 21 \%$ and $10 \%$ had partial remission (PR), stable disease (SD) and progressive disease (PD) respectively. The median PFS duration was 14 months and the median OS duration was 39 months. Stage VI, $\geq 3$ regimen of chemotherapy and bad response to LTBI (SD) affected progression duration adversely $(0.03,0.05$ and 0.01 respectively). The response to LTBI is the only factor af-

\footnotetext{
${ }^{*}$ Corresponding author.
} 
fected the OS duration significantly. The 3-year PFS was $19 \% \pm 9 \%$, and 3 -year OS was $45 \% \pm 8 \%$. Stage IV was the only factor affected the 3 -year PFS significantly with p value 0.03 . The hematological toxicity was the main side effect of LTBI. Eleven patients developed G3/4 anemia while 8 patients only developed G3/4 thrombocytopenia and 13 patients developed G3/4 leucopenia. Conclusion: The use of LTBI in patients with relapsed low grade NHL is a feasible, effective and tolerable treatment that is worthy of testing in a future with chemotherapy and Rituximab maintenance.

\section{Keywords}

Low Grade Non Hodgkin's Lymphoma [LG-NHL], Low Dose Total Body Irradiation [LTBI]

\section{Background}

The Low grade non Hodgkin Lymphoma (LG-NHL) represents about 35\% of all malignant lymphomas [1]. In general, these diseases are characterized by a slow clinical pace and by responsiveness to a variety of treatment approaches; relapse is essentially inevitable in advanced stage. In relapsed or refractory patients to initial therapy, the response to different chemotherapy combinations is transient and long-term survival is rarely seen [2]. High-dose therapy with stem cell support may improve the response, but the impact on survival is not well established [3].

The use of Low-dose total body irradiation (LTBI) for treating LG-NHL started at the beginning of the twenties of previous century. The interest of using LTBI compared to total nodal and subtotal nodal irradiation is mainly attributed to the evidence of having different mode of action on the cancer cells rather than direct cell kill. Experimental data suggest that the mode of action could be explained by 3 mechanisms namely; induction of apoptosis [4], intrinsic hypersensitivity to low radiation doses [5] and immune-enhancement [6].

The evidence of clinical efficiency of LTBI in LG-NHL grows from the late sixties and early seventies with the use of very low individual TBI fraction sizes ( $0.1-0.25 \mathrm{~Gy})$ given several times a week until a cumulative dose of approximately 1.5 - 2 Gy is reached [7]-[9]. The objective of this study is to report the National Cancer Institute, Cairo (NCI, Cairo) experience in treating relapsed LG-NHL patients with LTBI.

\section{Materials and Methods}

The medical records of the patients with low grade NHL received LTBI at NCI, Cairo and Damieta cancer institute (DCI) were reviewed. The patients subjected to the staging work up as per the NCI, Cairo guidelines including CT neck, chest, abdomen and pelvis. Bone marrow and complete lab including differential blood count and chemistry were routinely done for all patients before LTBI protocol.

LTBI consisted of two cycles; each one of $0.8 \mathrm{~Gy} / 4$ fractions/4 days; $0.2 \mathrm{~Gy}$ per fraction. The 2 cycles separated by 2 weeks rest. The total dose is 1.6 Gy over 4 weeks. LTBI was given by AP/PA technique and the dose was calculated to the patient's midline at the level of the umbilicus using the patient translation and beam zone method [10]. Dose homogeneity along the patient's midline was estimated to be $\pm 7 \%$. An alternative technique was used; the semi setting position with extended SSD technique of 4 meter distance at DCI with homogeneity $\pm 15 \%$. No lung shielding or compensators were implemented [11].

LTBI is given if WBCs $\geq 3.0 \times 10^{9} / \mathrm{L}$; platelets $\geq 100 \times 10^{9} / \mathrm{L}$ and hemoglobin above $10 \mathrm{~g} / \mathrm{dl}$. The blood sample were taken before $1^{\text {st }}$ and $2^{\text {nd }}$ radiotherapy cycles of LTBI, and then after 2 weeks from the end of LTBI. Blood samples were taken in the patients who developed hematological toxicity on weekly basis till complete recovery. The best supportive care for the patients who developed haematological toxicity as per the NCI Cairo guidelines were offered.

Patients with bulky disease $(10 \mathrm{~cm})$ received additional involved-field radiotherapy (IFRT) to the initial bulky sites. The IFRT dose ranges from 25 to $35 \mathrm{~Gy}$ as per the field size and disease burden after LTBI and was given as daily 1.8 to 2 Gy per fraction, five times a week starting 4 - 6 weeks after the end of LTBI.

Disease parameters and tumour responses were defined and evaluated according to the WHO criteria [12]. Response evaluation was done after 2 month from the end of whole treatment. CR stated for complete remission, PR for partial remission, SD for stable disease and PD for progressive disease. The assessment of response was carried out by the same tools of staging work up. Patients were followed monthly for the first 2 years then every 3 months thereafter. 


\section{Statistical Analysis}

The progression free survival (PFS) was calculated from the date of documented CR/PR to the date of first sign of progression. Overall survival (OS) calculated from $1^{\text {st }}$ LTBI fraction to the date of death or last follow-up. The following prognostic factors were studied; age, sex, B symptoms, Ann Arbor stage (II/III vs IV), involved field radiotherapy, performance status, response to LTBI (CR/PR vs SD/PD), extranodal presentation and the presence of bulky disease.

The estimate of survival was performed with the Kaplan-Meier method. The log-rank test was used to analyze survival differences among subgroups of patients. The paired T-test, Chi square and Fisher exact tests were used for testing proportion and to compare variables. Level of statistical significance is considered $<0.05$. Statistical software used was the SPSS for windows.

\section{Results}

Fifty eight patients proved to be LG-NHL out of 202 patients treated using LTBI during the period from 1997 till 2006 were retrospectively analyzed. The pathological subtypes include small cell lymphocytic lymphoma (13 patients), follicular lymphoma (33 patients), and marginal zone lymphomas and others (12 patients).

The patients' age ranged from 39 to 67 years with a median age of 54 years. There were 38 (65\%) men and 20 (35\%) women. Forty patients (69\%) had a WHO performance status of 2. Eight patients (14\%) were stage 2, 19 patients (33\%) stage III and 31 patients (53\%) had stage IV disease. Twenty six patients (45\%) had bulky disease (nodal or extranodal) and B symptoms were present in 22 (38\%) patients. The extranodal disease is present in 17 patients (29\%). Twenty three patients received IFRT out of the 26 patients presented by bulky disease. The 3 patients skipped the IFRT due to development of PD during the LTBI course. The mean dose of IFRT was 32 \pm 4 Gy. The patients received one to four different types of chemotherapy regimens and from 6 to 32 courses before referral to radiation oncology department. Patients' characteristics are summarized in Table 1.

\subsection{Response and Survival Evaluation}

The response rate is $69 \%$. Fourteen patients achieved CR (24\%), while 26 patients had PR (45\%), 12 patients had SD (21\%) and $6(10 \%)$ progressed during the treatment course.

The follow up duration ranges from 10 to 73 months (mean $42 \pm 17$ month). The median PFS duration was 14 months and the median OS duration was 39 months. The effect of different prognostic factors on survival is illustrated in Table 2.

Stage, number of chemotherapy regimens and response to LTBI affected progression free duration significantly $(0.03,0.05$ and 0.01 respectively). The response to LTBI is the only factor affected the OS duration significantly; the CR/PR patients showed 49 month median survival compared to 28 month for SD patients (p value 0.05). However the data should be taken cautiously due to the inhomogeneous distribution between the groups of patients.

The 3-year PFS was $19 \% \pm 9 \%$ as shown in Figure 1 and 3-year OS was $45 \% \pm 8 \%$ as shown in Figure 2 . The effect of disease bulk, IFRT and stage were studied. The other factors excluded due to inhomogeneous distribution and small number of patients (Table 3). The stage before LTBI is the only factor affected the 3-year PFS significantly with p value 0.03 .

\subsection{The Toxicity of LTBI}

The hematological toxicity was the main side effect for LTBI. Toxicity grading was done according to the Common Toxicity Criteria as shown in Table 4. The LTBI treatment is tolerable with no acute side effects that affect completion of the planned treatment schedule. Eleven patients developed G3/4 anemia while 8 patients only developed G3/4 thrombocytopenia and 13 patients developed G3/4 leucopenia. The median duration for leucopenia, anemia and thrombocytopenia was 5, 9 and 12 weeks respectively. No patients received growth factors and only 5 patients received blood elements transfusion.

\section{Discussion}

It is interesting that many new chemotherapeutic agents and monoclonal antibodies had failed to eradicate an apparently sensitive disease; low grade lymphoma. Even the median survival did not improve in the last 3 dec- 


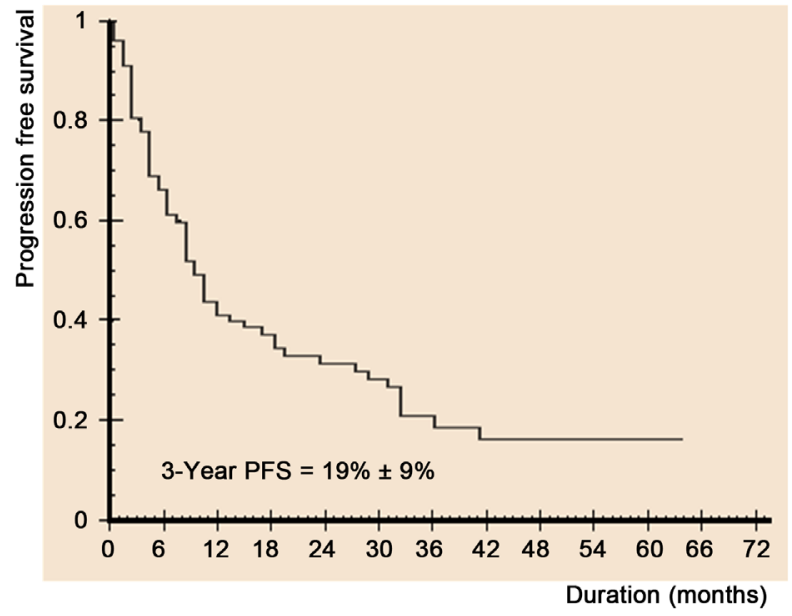

Figure 1. Progression free survival for 58 patients with relapsed low grade non-Hodgkin's lymphoma received low dose total body irradiation.

Table 1. Patient characteristics and prognostic factors.

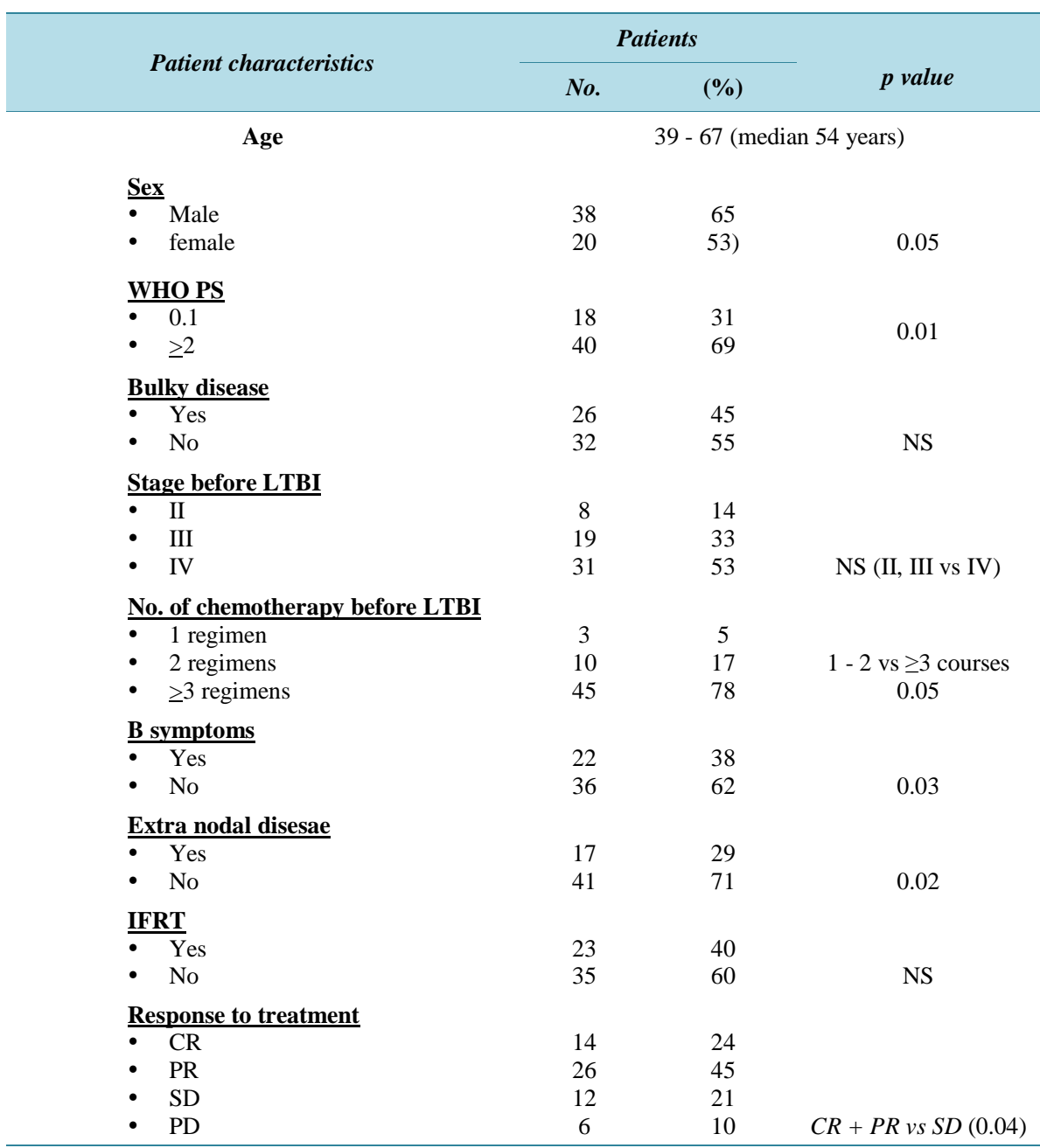

NS, non-significant; CR, complete remission; PR, partial remission; SD, stable disease; PD, progressive disease; IFRT, involved field radiotherapy; PS, performance status. 


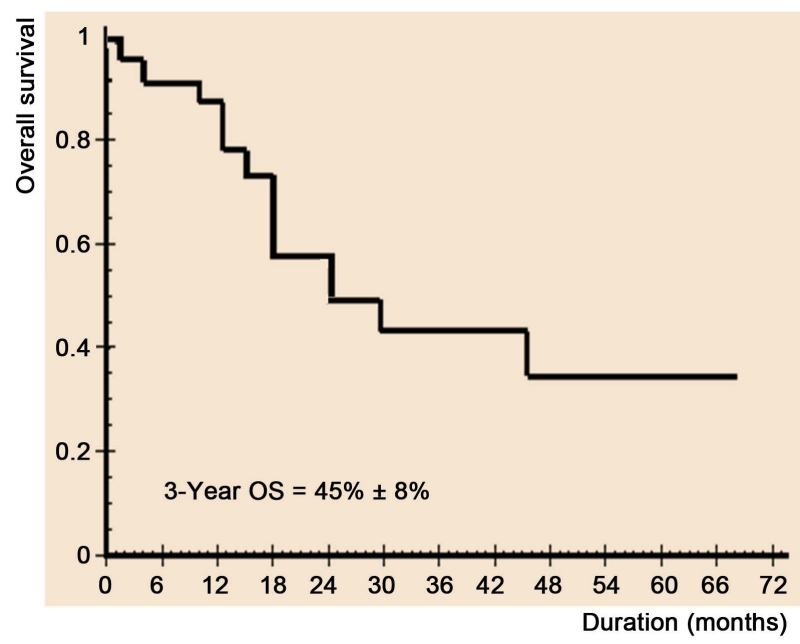

Figure 2. Overall survival for 58 patients with relapsed low grade non-Hodgkin's lymphoma received low dose total body irradiation.

Table 2. Median survival duration and the effect of different prognostic factors.

\begin{tabular}{|c|c|c|c|c|c|}
\hline \multirow{2}{*}{ Prognostic factor } & \multirow{2}{*}{$\begin{array}{l}\text { Pts } \\
\text { No. }\end{array}$} & \multicolumn{4}{|c|}{ Median survival duration in months } \\
\hline & & PFS & $p$ & OS & $p$ \\
\hline All patients & 58 & 14 & - & 39 & - \\
\hline $\begin{array}{l}\frac{\text { Sex }}{-} \text { Male } \\
-\quad \text { female }\end{array}$ & $\begin{array}{l}38 \\
20\end{array}$ & $\begin{array}{l}13 \\
16\end{array}$ & NS & $\begin{array}{l}34 \\
40\end{array}$ & NS \\
\hline $\begin{array}{l}\text { WHO PS } \\
-0.1 \\
\cdot \quad \geq 2\end{array}$ & $\begin{array}{l}18 \\
40\end{array}$ & $\begin{array}{l}29 \\
11\end{array}$ & NS & $\begin{array}{l}50 \\
36\end{array}$ & NS \\
\hline $\begin{array}{ll}\text { Bulky disease } \\
- & \text { Yes } \\
\cdot & \text { No }\end{array}$ & $\begin{array}{l}26 \\
32\end{array}$ & $\begin{array}{l}12 \\
15\end{array}$ & NS & $\begin{array}{l}39 \\
40\end{array}$ & NS \\
\hline \begin{tabular}{ll}
\multicolumn{2}{l}{ Stage before LTBI } \\
- & II/III \\
$\bullet$ & IV
\end{tabular} & $\begin{array}{l}27 \\
31\end{array}$ & $\begin{array}{l}20 \\
11\end{array}$ & 0.03 & $\begin{array}{l}49 \\
30\end{array}$ & NS \\
\hline $\begin{array}{l}\text { No. of chemotherapy } \\
\text { - } 1 \text { - } 2 \text { regimen } \\
\text { > } 3 \text { regimen }\end{array}$ & $\begin{array}{l}13 \\
45\end{array}$ & $\begin{array}{c}23 \\
9\end{array}$ & 0.05 & $\begin{array}{l}53 \\
24\end{array}$ & NS \\
\hline \begin{tabular}{ll}
\multicolumn{3}{l}{ B symptoms } \\
- & Yes \\
- & No
\end{tabular} & $\begin{array}{l}22 \\
36\end{array}$ & $\begin{array}{l}13 \\
18\end{array}$ & NS & $\begin{array}{l}33 \\
44\end{array}$ & NS \\
\hline $\begin{array}{ll}\text { Extra nodal disesae } \\
& \text { Yes } \\
- & \text { No }\end{array}$ & $\begin{array}{l}17 \\
41\end{array}$ & $\begin{array}{l}10 \\
19\end{array}$ & NS & $\begin{array}{l}21 \\
44\end{array}$ & NS \\
\hline $\begin{array}{ll}\text { IFRT } \\
\text { Yes } \\
-\quad \text { No }\end{array}$ & $\begin{array}{l}23 \\
35\end{array}$ & $\begin{array}{l}13 \\
17\end{array}$ & NS & $\begin{array}{l}32 \\
43\end{array}$ & NS \\
\hline \begin{tabular}{ll}
\multicolumn{2}{l}{ Response to LTBI } \\
- & $\mathrm{CR} / \mathrm{PR}$ \\
- & $\mathrm{SD}$
\end{tabular} & $\begin{array}{l}40 \\
12\end{array}$ & $\begin{array}{c}24 \\
7\end{array}$ & 0.01 & $\begin{array}{l}49 \\
28\end{array}$ & 0.05 \\
\hline
\end{tabular}

NS, non-significant; CR, complete remission; PR, partial remission; SD, stable disease; PD, progressive disease; IFRT, involved field radiotherapy; PS, performance status. 
Table 3. 3-year progression free survival and overall survival for the patients with the effect of homogenously distributed prognostic factors.

\begin{tabular}{|c|c|c|c|c|}
\hline Prognostic factor & 3y-PFS & $\mathbf{p}$ & $3 y-O S$ & $\mathbf{p}$ \\
\hline All patients & $19 \pm 9$ & - & $45 \pm 8$ & - \\
\hline \multicolumn{5}{|l|}{ Bulky disease } \\
\hline Yes & $17 \pm 9$ & & $39 \pm 7$ & \\
\hline No & $20 \pm 8$ & NS & $57 \pm 10$ & NS \\
\hline \multicolumn{5}{|l|}{ IFRT } \\
\hline Yes & $24 \pm 8$ & & $48 \pm 9$ & \\
\hline No & $16 \pm 9$ & NS & $40 \pm 7$ & NS \\
\hline \multicolumn{5}{|l|}{ Stage before LTBI } \\
\hline II/III & $25 \pm 6$ & & $53 \pm 13$ & \\
\hline IV & $15 \pm 11$ & 0.03 & $41 \pm 8$ & NS \\
\hline
\end{tabular}

PFS = progression free survival, OS = overall survival, IFRT = involved field radiotherapy.

Table 4. Common toxicity criteria.

\begin{tabular}{cccc}
\hline Grade & WBCs $\left(\times \mathbf{1 0}^{\mathbf{3}} / \boldsymbol{\mu l}\right)$ & Platelet $(\times \mathbf{1 0} \mathbf{3} / \boldsymbol{\mu l})$ & HgB $(\mathbf{g} / \mathbf{d l})$ \\
\hline 0 & Normal & Normal & Normal \\
1 & $3-4$ & $>75$ & $>10.0$ \\
2 & $2-3$ & $50-75$ & $8.0-10$ \\
3 & $1-2$ & $25-50$ & $6.5-8$ \\
4 & $<1$ & $<25$ & $<6.5$ \\
\hline
\end{tabular}

ades without any superiority of bone marrow transplantation regimens at least for refractory cases. Most of the studies using new chemotherapeutic drugs for relapsed indolent NHL showed progression free survival at 5 years ranges from $20 \%$ to $40 \%$ [13]-[15].

The LTBI is a well known historical method of treating the relapsed LG-NHL. Yonkosky et al., treated 9 relapsed NHL with fractionated LTBI (1.2 - 1.8 Gy) and reported CR rate more than 50\% which is higher than our data that showed CR rate 24\% only [16]. Also, Jacobs and King randomized 108 patients with indolent NHL and CLL between CP and LTBI. The CR rate for LTBI group ( $\mathrm{n}=54), 52 \%$ and median survival was 57 months [17].

Apart from the proved equal effect of LTBI and chemotherapy in Jacobs and King study, the better CR rate in LTBI arm in their study compared to our cases is mainly attributed to the difference between the 2 the 2 studies in patient characteristics, as we targeted the relapsed and refractory cases while Jacobs and King targeted the new and patients in $1^{\text {st }}$ relapse. Also in our study; 45 out of 58 patients received 3 lines or more of chemotherapy and 40 patients out of 58 patients had bad performance status ( 2 or more).

There are some similarities between the results of our study and the one by Carabell et al. who treated 58 patients with stage III or IV by a total dose of 1.5 Gy/10 fractions; 2 fractions per week. Survival at 8 years was $52 \%$ with $14 \%$ relapse free survival compared to $45 \%$ and $19 \%$ respectively in our group of patients. The median PFS duration was 14 month in our data compared to 24 month for Carabell data. [18].

Meerwaldet treated 44 low grade lymphoma patients by LTBI (1.5 Gy) and 40 patients by CHVmP. The 5year PFS was $15 \%$ for LTBI compared to $19 \%$ in our study and the 5 -year OS was $45 \%$ for (LTBI) which is similar to our study. Surprisingly enough, the chemotherapy (CHVmP) arm had PFS 25\% which is not far beyond the results of LTBI in the same study [19].

Studying the prognostic factors in our patients received LTBI proved that stage is the only factor affected the 3-year PFS significantly with p value 0.03 .

The median duration for progression affected significantly by stage also in addition to number of chemotherapy regimen given before referral to LTBI and response to LTBI.

The response to LTBI is the only factor affected the OS duration significantly; the CR/PR patients showed 49 
month median survival compared to 28 month for SD patients ( $\mathrm{p}$ value 0.05 ).

These results are comparable to previously published studies addressing the same issue. Lybeert et al. showed that prior treatment, stage and sex had no influence on survival. Age was reversibly correlated with survival but not with PFS. On the other hand, low grade lymphoma patients had a significantly better PFS if they received LTBI as a primary therapy but survival was not significantly influenced [20].

In another study, previous treatment decreased PFS by univariate analysis $(p=0.066)$. Multivariate analysis identified the best indicators of response rate to be histology, and marrow involvement. The best indicators of PFS were histology, and TBI dose. The best indicators for survival were age histology and TBI dose [21].

The trials compared LTBI with chemotherapy showed comparable results as stated by Jacobs/King, Meerwaldet and Safwat [17] [19] [22].

Even one of the widely used therapeutic agent in relapsed indolent lymphoma-Rituximab-having $40 \%$ to $50 \%$ response rate [23] [24] which is comparable to the LTBI results. The longer response duration of Rituximab could be justified by the idea of maintenance therapy in most of trials of Rituximab.

Three randomized, prospective studies randomized relapsed LG-NHL to rituximab maintenance vs none after retreatment with combination chemotherapy including Rituximab in the initial treatment; all trials showed prolongation of response duration and median duration of PFS (43 months vs. 15 months) in favor of Rituximab maintenance [25]-[27]. These data are still comparable to our data, as the PFS duration was 15 month in the arm without Rituximab maintenance compared to 14-month in our study.

The overall response rate in our study is around $69 \%$ however; there is clear evidence in the literature that combining LTBI with chemotherapy gave better results. The results of prospective pilot trial combining LTBI (100 - 150 rads) with chemotherapy (CVP or C-MOPP) for previously untreated, stage II-IV, low-grade NHL patients [28] showed good results in terms of overall response $(86 \%$ - 90\%) and complete remission rates (60\% 80\%). Also combination of LTBI and Prednimustine were evaluated in relapsed low-grade NHL patients. Six to nine courses of Prednimustine were given 2 months after a 1.5 Gy LTBI as consolidation therapy. The overall response rate was around $85 \%$. The complete remission rate occurred in $12.5 \%$ and $24.30 \%$ in the CLL and LG-NHL patients respectively [29].

The philosophy of using immune-modulators and maintenance therapy in relapsed LG-NHL is gaining popularity in the last decades. Currently, the immune-modulatory effect of LTBI is well known as mentioned previously [6] and proved by NCI, Cairo publications in NHL and metastatic renal cell carcinoma cases [30]-[32].

\section{Conclusions and Recommendations}

LTBI, however it is underutilized, it is tolerable and effective palliative treatment for relapsed LG-NHL even for refractory and resistant cases with bad prognostic factors. The effect is comparable to chemotherapy regarding the response rate and progression free survival.

Based on its efficacy and different mode of action against cancer cells, LTBI can be combined to chemotherapy and Rituximab maintenance and tested in multi institutional prospective study.

\section{Acknowledgements}

The authors would like to thank Dr. Akmal Safwat for his precious advices and support during the whole work. Dr. Akmal shared with us in our previous trials using LTBI in NHL at NCI and we learned a lot from him.

\section{References}

[1] American Cancer Society (2014) Cancer Facts and Figures 2014. American Cancer Society, Atlanta.

[2] Klasa, R.J., Meyer, R.M., Shustik, C., et al. (2002) Randomized Phase III Study of Fludarabine Phosphate versus Cyclophosphamide, Vincristine, and Prednisone in Patients with Recurrent Low-Grade Non-Hodgkin's Lymphoma Previously Treated with an Alkylating Agent or Alkylator-Containing Regimen. Journal of Clinical Oncology, 20, 46494654. http://dx.doi.org/10.1200/JCO.2002.11.068

[3] Thomson, K.J., Morris, E.C., Milligan, D., et al. (2010) T-Cell-Depleted Reduced-Intensity Transplantation Followed by Donor Leukocyte Infusions to Promote Graft-versus-Lymphoma Activity Results in Excellent Long-Term Survival in Patients with Multiply Relapsed Follicular Lymphoma. Journal of Clinical Oncology, 28, 3695-3700. http://dx.doi.org/10.1200/JCO.2009.26.9100

[4] Delic, J., Magdelenat, H., Barbaroux, C., et al. (1995) In-Vivo Induction of Apoptosis in Human Lymphocyes by The- 
rapeutic Fractionated Total Body Irradiation. British Journal of Radiology, 68, 997-1003. http://dx.doi.org/10.1259/0007-1285-68-813-997

[5] Marples, B., Lambin, P., Skov, K.A., et al. (1997) Low-Dose Hypersensitivity and Induced Radioresistance in Mammalian Cells. International Journal Radiation Biology, 71, 721-735. http://dx.doi.org/10.1080/095530097143725

[6] Hashimoto, S. (1997) Effects of Low-Dose Total Body Irradiation on Tumour Bearing Rats. Nippon Igaku Hoshasen Gakkai Zasshi, 57, 418-424.

[7] Rees, G.J., Bullimore, J.A. and Lever, J.V. (1980) Total Body Irradiation as a Secondary Therapy in Non-Hodgkin’s Lymphoma. Clinical Radiology, 31, 437-439. http://dx.doi.org/10.1016/S0009-9260(80)80185-1

[8] van Dijk-Miatz, A. (1979) Total Body Irradiation in Advanced Lymphosarcoma. British Journal of Radiology, 52, 568570. http://dx.doi.org/10.1259/0007-1285-52-619-568

[9] Chaffey, J.T., Rosenthal, D.S., Pinkus, G., et al. (1975) Advanced Lymphosarcoma Treated by Total Body Irradiation. British Journal of Cancer, 31, 441-449.

[10] Quast, U. (1985) Physical Treatment Planning of Total Body Irradiation: Patient Translation and Beam Zone Method. Medical Physics, 12, 567-573. http://dx.doi.org/10.1118/1.595677

[11] Quast, U. (1987) Total Body Irradiation-Review of Treatment Techniques in Europe. Radiotherapy \& Oncology, 9, 91-106. http://dx.doi.org/10.1016/S0167-8140(87)80197-4

[12] (1979) WHO Handbook for Reporting Results of Cancer Treatment. WHO off Set Publication, Geneva.

[13] Hochster, H.S., Kim, K.M., Green, M.D., et al. (1992) Activity of Fludarabine in Previously Treated Non-Hodgkin's Low-Grade Lymphoma: Results of an Eastern Cooperative Oncology Group Study. Journal of Clinical Oncology, 10, 28-32.

[14] Kay, A.C., Saven, A., Carrera, C.J., et al. (1992) 2-Chlorodeoxyadenosine Treatment of Low-Grade Lymphomas. Journal of Clinical Oncology, 10, 371-377.

[15] Redman, J.R., Cabanillas, F., Velasquez, W.S., et al. (1992) Phase II Trial of Fludarabine Phosphate in Lymphoma: An Effective New Agent in Low-Grade Lymphoma. Journal of Clinical Oncology, 10, 790-794.

[16] Yonkosky, D.M., Feldman, M.I., Cathcart, E.S. and Kim, S. (1978) Improvement of in Vitro Mitogen Proliferative Reponses in Non-Hodgkin's Lymphoma Patients Exposed to Fractionated Total Body Irradiation. Cancer, 42, $1204-$ 1210. http://dx.doi.org/10.1002/1097-0142(197809)42:3<1204::AID-CNCR2820420325>3.0.CO;2-S

[17] Jacobs, P. and King, H.S. (1987) A Randomised Prospective Comparison of Chemotherapy to Total Body Irradiation as Initial Treatment for the Indolent Lymphoproliferative Diseases. Blood, 69, 1642-1646.

[18] Carabell, S.C., Chaffey, J.T., Rosenthal, D.S., et al. (1979) Results of Total Body Irradiation in the Treatment of Advanced Non-Hodgkin's Lymphoma. Cancer, 43, 994-1000. http://dx.doi.org/10.1002/1097-0142(197903)43:3<994::AID-CNCR2820430331>3.0.CO;2-0

[19] Meerwaldt, J.H., Carde, P., Burgers, J.M.V., et al. (1991) Low-Dose Total Body Irradiation versus Combination Chemotherapy for Lymphomas with Follicular Growth Pattern. International Journal of Radiation Oncology Biology Physics, 21, 1167-1172. http://dx.doi.org/10.1016/0360-3016(91)90272-6

[20] Lybeert, M.L.M., Meerwaldt, J.H. and Deneve, W. (1987) Long Term Results of Low Dose Total Body Irradiation for Advanced Non-Hodgkin's Lymphoma. International Journal of Radiation Oncology Biology Physics, 13, 1845-1852.

[21] Roncadin, M., Arcicasa, M., Bortolus, R., et al. (1991) Feasibility of Total Body Irradiation in Chronic Lymphocytic Leukemia and Low Grade Non-Hodgkin's Lymphomas. Cancer Investigation, 9, 403-407. http://dx.doi.org/10.3109/07357909109084637

[22] Safwat, A. (2000) The Role of Low-Dose Total Body Irradiation in Treatment of NHL: A New Look at an Old Method. Radiotherapy \& Oncology, 56, 1-8. http://dx.doi.org/10.1016/S0167-8140(00)00167-5

[23] Piro, L.D., White, C.A., Grillo-López, A.J., et al. (1999) Extended Rituximab (Anti-CD ${ }_{20}$ Monoclonal Antibody) Therapy for Relapsed or Refractory Low-Grade or Follicular Non-Hodgkin's Lymphoma. Annals of Oncology, 10, 655-661. http://dx.doi.org/10.1023/A:1008389119525

[24] Davis, T.A., Grillo-López, A.J., White, C.A., et al. (2000) Rituximab Anti- $\mathrm{CD}_{20}$ Monoclonal Antibody Therapy in Non-Hodgkin's Lymphoma: Safety and Efficacy of Re-Treatment. Journal of Clinical Oncology, 18, 3135-3143.

[25] van Oers, M.H., Van Glabbeke, M., Giurgea, L., et al. (2010) Rituximab Maintenance Treatment of Relapsed/Resistant Follicular Non-Hodgkin's Lymphoma: Long-Term Outcome of the EORTC 20981 Phase III Randomized Intergroup Study. Journal of Clinical Oncology, 28, 2853-2858. http://dx.doi.org/10.1200/JCO.2009.26.5827

[26] Martinelli, G., Schmitz, S.F., Utiger, U., et al. (2010) Long-Term Follow-Up of Patients with Follicular Lymphoma Receiving Single-Agent Rituximab at Two Different Schedules in Trial SAKK 35/98. Journal of Clinical Oncology, 28, 4480-4484. http://dx.doi.org/10.1200/JCO.2010.28.4786

[27] van Oers, M.H., Klasa, R., Marcus, R.E., et al. (2006) Rituximab Maintenance Improves Clinical Outcome of Re- 
lapsed/Resistant Follicular Non-Hodgkin Lymphoma in Patients Both with and without Rituximab during Induction: Results of a Prospective Randomized Phase 3 Intergroup Trial. Blood, 108, 3295-3301.

http://dx.doi.org/10.1182/blood-2006-05-021113

[28] Young, R.C., Johnson, R.E., Canellos, G.P., et al. (1977) Advanced Lymphocytic Lymphoma: Randomized Comparisons of Chemotherapy and Radiotherapy, Alone or in Combination. Cancer Treatment Reports, 61, 1153-1159.

[29] Roncadin, M., Arcicasa, M. and Zagonel, V. (1994) Total Body Irradiation and Prednimustine in Chronic Lymphocytic Leukemia and Low Grade Non-Hodgkin’s Lymphoma: A 9-Year Experience in a Single Institution. Cancer, 74, 978984. http://dx.doi.org/10.1002/1097-0142(19940801)74:3<978::AID-CNCR2820740330>3.0.CO;2-B

[30] Bayoumi, Y., Radwan, A. and El Sharkawi, N. (2008) Low Dose Total Body Irradiation in Patients with Metastatic Renal Cell Carcinoma: A Feasibility Study and Immunomodulatory Effect. Medical Journal of Cairo University, 76, 261-266.

[31] Safwat, A., Bayoumi, Y., El-Sharkawy, N., Shaaban, K., et al. (2003) The Potential Palliative Role and Possible Immune Modulatory Effects of Low-Dose Total Body Irradiation in Relapsed or Chemo-Resistant NHL. Radiotherapy and Oncology, 69, 33-36. http://dx.doi.org/10.1016/S0167-8140(03)00247-0

[32] Safwat, A., Bayoumi, Y., Akkoush, H. and Mahmoud, H.K. (2004) A Phase II Trial of Adjuvant Low-Dose Total Body Irradiation in Non-Hodgkin's Lymphoma Patients Following Standard CHOP. Acta Oncologica, 43, 480-485. 
Scientific Research Publishing (SCIRP) is one of the largest Open Access journal publishers. It is currently publishing more than 200 open access, online, peer-reviewed journals covering a wide range of academic disciplines. SCIRP serves the worldwide academic communities and contributes to the progress and application of science with its publication.

Other selected journals from SCIRP are listed as below. Submit your manuscript to us via either submit@scirp.org or Online Submission Portal.
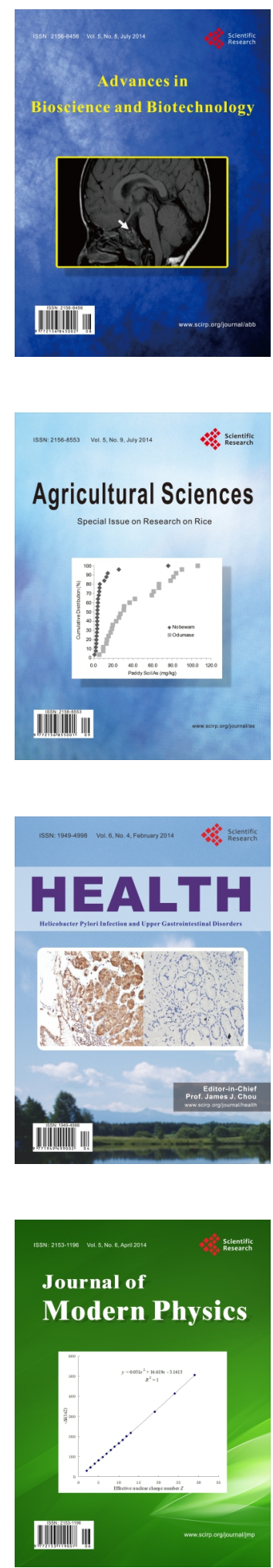
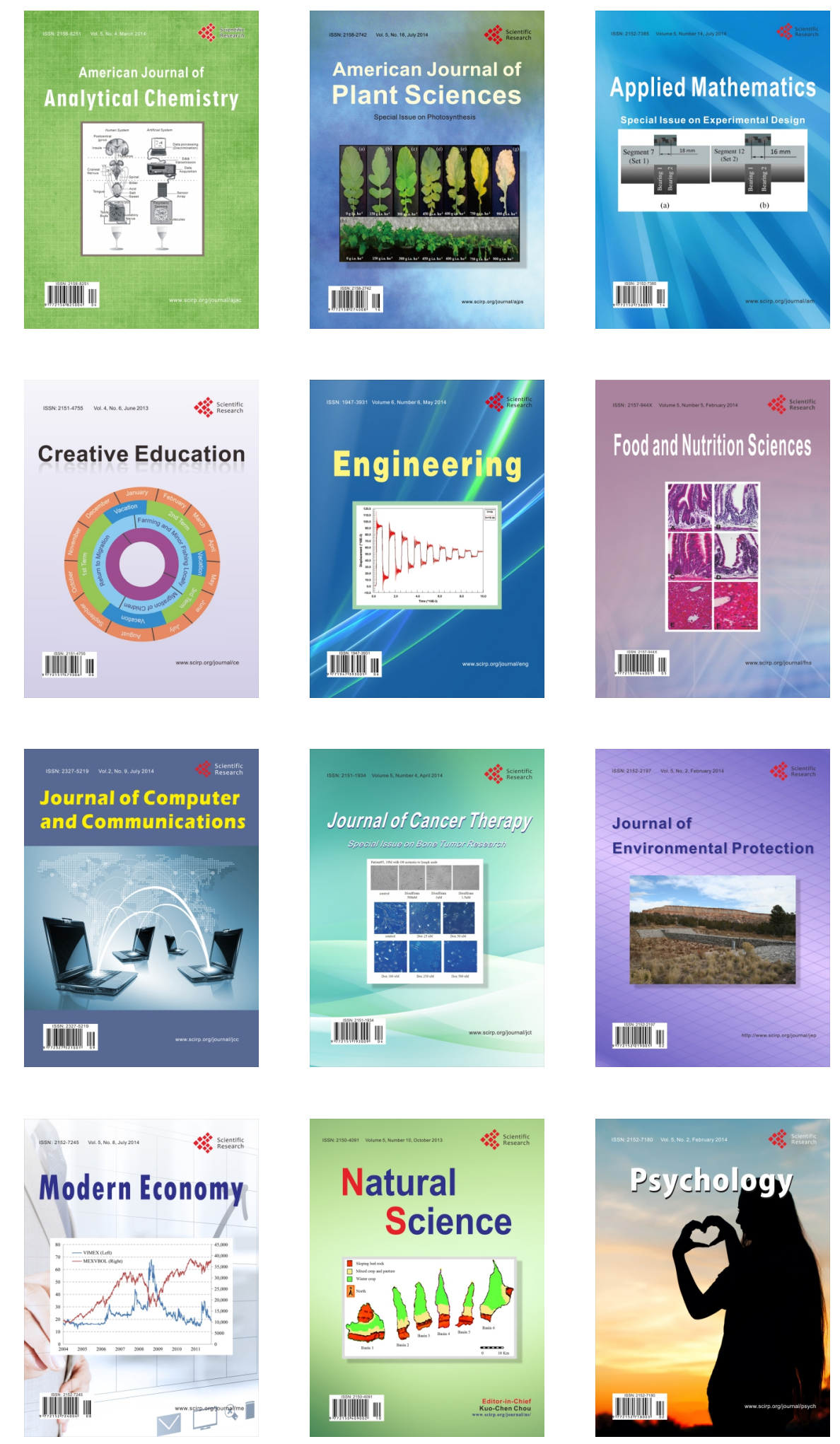